\author{
Аксенова К. А., Оборотова Е. В.
}

\begin{abstract}
Аннотация. Цель исследования - определить основные свойства итальянских квантификаторов неопределённо большого количества. В статье рассматривается процесс грамматикализации количественных лексем как основной метод образования квантификаторов. Основное внимание уделяется распределению итальянских квантификаторов по шкале их грамматикализации. Научная новизна работы состоит в том, что в ней впервые рассматривается квантитативная лексика итальянского языка сквозь призму грамматической репрезентации концепта НЕОПРЕДЕЛЕННОЕ КОЛИЧЕСТВО. В результате выделены и охарактеризованы три степени грамматикализации (минимальная, средняя и максимальная), а также квантификаторы распределены по шкале грамматикализации в соответствии со степенью грамматикализованности рассматриваемых нами лексических имён.
\end{abstract}

\title{
EN Peculiarities of Grammaticalization of the Italian Quantifiers of Indefinitely Big Quantity
}

\author{
Aksenova K. A., Oborotova E. V.
}

\begin{abstract}
The paper aims to identify peculiarities of the Italian quantifiers of indefinitely big quantity. Grammaticalization of quantitative lexemes is considered as a basic means to form quantifiers. The research objective is to develop a classification of the Italian quantifiers according to the degree of their grammaticalization. Scientific originality of the study lies in the fact that the Italian quantitative vocabulary is for the first time analysed through the lens of grammatical representation of the concept INDEFINITE QUANTITY. The research findings are as follows: the authors identify and describe three degrees of grammaticalization (minimum, average and maximum), propose a classification of the Italian quantifiers according to the degree of their grammaticalization.
\end{abstract}

\section{Введение}

Актуальность предпринятого исследования определяется в первую очередь тем, что концепт КОЛИЧЕСТВО является ключевым предметом изучения для самых разных наук. Языковые варианты воплощения количественных отношений многократно осмыслялись в разнообразных лексикологических исследованиях, проводимых с привлечением разнообразных языков мира. Однако степень изученности репрезентации данного концепта на материале итальянского языка не является удовлетворительной, на наш взгляд, в частности, вопрос об особенностях грамматического «поведения» квантитативных лексем итальянского языка представляет существенный интерес для современной когнитивной лингвистики.

Для достижения поставленной цели в ходе написания работы решался ряд определенных задач:

- составить список квантификаторов неопределённо большого количества на материале современного итальянского языка;

- обозначить основные степени грамматикализации итальянских квантитативных лексем;

- выявить степень грамматикализации исследуемых нами квантификаторов.

Для достижения обозначенной цели и решения конкретизирующих её задач в работе применялся структурный подход, основанный на сочетании следующих методов анализа материала: сопоставительнотипологический метод, контекстуальный анализ, метод компонентного анализа, метод словарных дефиниций, а также метод количественной обработки полученных результатов.

Теоретическую базу исследования составляют публикации Н. Хомского [6], Л. А. Шестака [10], Т. А. Фесенко [5], А. А. Челноковой [7], посвященные базовой метафорике в языковой картине мира, а также выражению 
разных видов количества в языке. Кроме того, учитывались работы С. О. Швачко [9] и Л. Д. Чесноковой [8], которые рассматривают концепт КОЛИЧЕСТВО через призму структуры его синтаксических особенностей. Важным аспектом исследования явилось рассмотрение особенностей лексической множественности, определение механизмов и этапов грамматикализации, что стало возможным благодаря трудам Е. В. Рахилиной и Ли Су Хён [1], Е. В. Федяевой [4], Дж. Дучес [11], Антуана Мейе [13], дающим описание семантики квантификаторов английского, русского и итальянского языков.

Практическая значимость исследования заключается в том, что полученные результаты могут быть использованы в вузах гуманитарного направления на теоретических и практических занятиях по сравнительной лингвистике английского, итальянского и русского языков, а также в спецкурсах и спецсеминарах по когнитивистике и психолингвистике. Полученные данные могут найти применение в процессе учебнометодической деятельности при создании учебников, учебных пособий, при составлении словарей разного типа, а также при написании курсовых и выпускных квалификационных работ.

Но если привычное, традиционное отражение отношений квантитативности отношений в языке, являющемся предметом нашего рассмотрения, описано чрезвычайно подробно и обширно, то более пристальный и детальный анализ количественных отношений в итальянском языке ещё не произведён и в силу этого достоин особого научного внимания.

\section{Итальянские квантификаторы неопределенно большого количества}

Категория количества, наряду с категориями качества, времени, пространства, состояния и др., является одним из ключевых компонентов языковой концептосферы. Количество - важнейший концептуальный элемент не только любого языка, но и самого человеческого мышления, с языком непосредственно и двусторонне связанного. В каждом конкретном языке история развития и становления данной категории индивидуальна, но есть и общие опорные точки её эволюции. Этой категорией занимались многие видные лингвисты. Сегодняшняя лингвистика также обращает на категорию количества самое пристальное внимание. Особенно важным для её изучения представляется компаративный подход, заключающийся в сравнении количественной категории в различных языках индоевропейской языковой семьи. Такие исследования позволяют выявить любопытную лингвистическую и культурологическую информацию, которая чрезвычайно значима и актуальна как для формулирования теоретических постулатов, так и для практических изысканий в указанном направлении языкового осмысления категории количества. Активно изучаются отдельные составляющие категорию количества языковые элементы, такие как: число, количественная этимология, имя числительное и многие другие.

«Количественные отношения, свойственные объективной действительности, познаются и вербализируются определённо, приблизительно и неопределённо» [6, с. 14]. Сама категория неопределённости является в первую очередь итогом некоторой, если не абсолютной, неопознанности и, более того, непознаваемости какого-либо объекта. Однако именно возникновение «неопределенного» в различных языках на более поздних этапах стало одним из ведущих достижений развитого когнитивного аппарата мышления.

Понятие о неопределённом количестве возникает тем же образом, как и понятие приблизительного множества, - на когнитивном уровне, но с ориентацией на объективную действительность. Следовательно, неопределенное множество соединяет в себе и черты определённого, и черты неопределённого множества.

Квантификативная достоверность окружающей реальности обнаруживается в семантическом поле любого развитого современного языка, таким образом, способы выражения некоего множества включают в себя все уровни языковой парадигмы: не только фразеологический и лексический уровни, но также словообразовательный, морфологический и синтаксический.

Данная работа анализирует квантитативную лексику современного итальянского языка. В качестве иллюстративного материала использовались данные, полученные методом сплошной выборки, из толкового словаря современного итальянского языка Н. Дзингарелли.

На исследования квантитативной лексики итальянского языка во многом повлияли работы Дж. Дучес. Именно она подчеркнула и акцентировала подход, в рамках которого квантификация анализируется как явление не только лексическое, но и грамматическое. Дж. Дучес делит квантификацию на два вида - конкретную, или определенную, и неконкретную, или неопределенную.

Согласно автору, конкретная квантификация формулируется с помощью конкретных чисел, в то время как квантификация неконкретного множества чаще всего претерпевает метафорический сдвиг, который, в свою очередь, указывает либо на определенное, либо неопределенное количество или число объектов, в этом случае квантификация имеет «расплывчатый» характер, она выражает лишь приблизительные способы квантифицировать явления или предметы, не обладающие очевидными количественными характеристиками. Дж. Дучес [11] также рассматривает так называемую поэтапную квантификацию (niente, poco, qualcosa, abbastanza, troppo ничего, мало, немного, довольно много, слишком много [14]) (здесь и далее перевод авторов статьи. - К. А., Е. О.).

Разумеется, в первую очередь такая часть речи, как числительное, способно полноценно выразить числовую квантитативность с учетом всех ее возможных вариантов проявлений. То же можно сказать о детерминативах в составе именных словосочетаний (cinque giorni, tra due e tre - пять дней, от двух до трех). Очевидно, что в таких случаях всегда наличествует отнесение к квантификативному, или количественному элементу 
высказывания, при этом дополнительных семантических оттенков, а следовательно, полноценной метафоризации не возникает, наблюдается лишь условная подчиненность контексту, и количественная семантика выражена максимально ёмко и определённо посредством числа.

Существенную роль в итальянском языке играет ситуация неопределенной квантификации - в таком случае индивидуально-субъективная оценка количества несёт на себе основной семантический «заряд», подвергающийся дополнительным нюансам и коннотациям: studiare con scarso interesse - он учится с вялым (недостаточным) интересом.

В таком случае Дж. Дучес видит необходимость говорить о так называемой нейтральной шкале, служащей основным фундаментом сопоставительного анализа. В дальнейшем мы будем говорить об этом подробнее в контексте различных ступеней и уровней грамматикализации. Именно наличие некоторой нулевой величины позволяет осуществить сравнение. Важно учитывать, что данное сравнение имеет сугубо субъективный характер, так как находится в непосредственной зависимости от того, какое представление имеет говорящий о некой средней величине [11, p. 13].

Основные виды квантификации, обозначенные Дж. Дучес, очевидно указывают на разнообразные уровни зависимости количественных лексем от контекста, такая условная зависимость проявляется в наименьшей степени при языковом воплощении конкретного числа и в наибольшей степени, то есть максимальной, в процессе сопоставительного анализа нескольких квантификативных имён.

Необходимо учесть, что представленная классификация охватывает узкий круг контекста квантификации, не включая в себя иные способы количественных отношений, при которых данное понятие воплощается в языке при помощи артиклей, местоимений и, несомненно, числительных.

В качестве объекта данного исследования мы рассматриваем существительные в конструкции di/de + N (cyществительное) (figurato massa di qualcosa). Причем в фокусе находятся именно предметные существительные.

При отборе лексики мы руководствовались следующей формулой, согласно которой квантификация «выступает как любое измерение объекта наименования, целью которой является отражение его количественных характеристик: квантификация по количеству - “сколько”, величине объекта наименования, по параметрам “большой - маленький” и т.д.; интенсивность; степень и т.п.» [3, с. 181], а также определением Эдуарда Сепира: «Квантификаторы - слова, которые отвечают на вопрос “Того-то и того-то сколько или то-то и то-то в какой степени?” $[2$, с. 164].

Например, spate (an unexpected sudden outpouring rush or increase - наводнение, разлив (реки) половодье) во фразе a spate of smth (множество ч.-л.) обозначает не отдельный объект, а неопределенно большое число объектов (ср.: The bombing was the latest in a spate of terrorist attacks [12]. / В череде террористических атак последним был взрыв).

Понятие грамматикализации мы трактуем в соответствии с формулировкой статьи «Эволюция грамматических форм» (начало XX века). Эта трактовка апеллирует к исследованиям Антуана Мейе, который писал о «приобретении грамматического статуса словом, бывшим до этого автономным» [13, p. 139].

По материалам толкового словаря итальянского языка Н. Дзингарелли, в итальянском языке насчитывается 29 квантитативных лексем неопределённо большого количества: abbondanza, afflusso, arma, bagaglio, branco, diluvio, esercito, fascio, fila, fiume, fortuna, frutto,grappolo, groviglio, invasione, manica, marea, mondo, montagna, mucchio, nuvola, oceano, pioggia, raffica, spazzatura, squadra, valanga, voragine, vortice - изобилие, наплыв, корпус, багаж, банда, поток, армия, стопка, ряд, река, состояние, плоды, гроздья, клубок, нашествие, стайка, море, мир, гора, куча, облако, океан, град, шквал, мусор, команда, лавина, пропасть, вихрь [14].

Данные списки составляют исключительно предметные существительные, слова «много» типа esercito, ricchezza, madria (армия, богатство, табун) не входят в поле нашего научного интереса, так как их семантика уже передает идею неопределенного множества.

В статье Е. В. Рахилиной и Ли Су Хен, которую мы брали в качестве основы нашего научного исследования, даны русские лексемы, чья локализации неравномерна по шкале грамматикализации. Например, имя «копна» минимально грамматикализовано, поскольку данное слово может сочетаться только с лексемой «волосы» в значении «очень много волос». Другие сочетания для данной лексической единицы невозможны мы не скажем «копна цветов» или «копна проблем» [1, с. 18].

Другим «препятствием» на пути грамматикализации являются абстрактные существительные. Однако такая «преграда» на самом деле преодолевается проще, поскольку здесь мы имеем дело с устойчивыми метафорическими сочетания: например, решения, вопросы, ситуации, события сопоставляются с неопределенно большим множеством предметов - ср. груда проблем, гора дел и др., чувства - с водоемами (море любви, океан счастья) и т.д.

Данные вопросы применительно к количественным именам в современном итальянском языке будут рассмотрены ниже.

Среди наименее грамматикализованных лексем мы выделяем следующие имена: arma, bagaglio, branco, esercito, manica - корпус, багаж, банда, армия, рукав.

Например:

arma

1. spada, fucile, pistola. L'arma del delitto è sicuramente una pistola [14, p. 132]. / Орудие убийства - это, безусловно, пистолет.

2. parte delle forze armate. Ormai da diversi anni anche le donne sono ammesse nell'arma [Ibidem]. / Уже несколько лет женщины также допускаются в ряды служащих. 


\section{bagaglio}

1. contenitore per viaggiare. A Luca fu chiesto di aprire il bagaglio alla dogana per un controllo [Ibidem, p. 143]. / Луку попросили открыть багаж на таможне для проверки.

2. figurato patrimonio di. Quell'esperienza all'estero ha molto accresciuto il suo bagaglio professionale [Ibidem]. / Этот опыт за границей значительно увеличил его профессиональный багаж.

На другом полюсе нашей шкалы находятся лексические единицы, которые предельно грамматикализованы: diluvio, fiume, marea, mondo, montagna, mucchio, oceano, pioggia, raffica, valanga - поток, река, море, мир, гора, куча, океан, град, шквал, лавина.

\section{fiume}

1. corso d'acqua. Mi piace nuotare nel fiume [Ibidem, p. 201]. / Мне нравится плавать в реке.

2. figurato fluido: grande quantità. Il vino scorreva nel fiume [Ibidem]. / Вино лилось рекой.

3. figurato grande flusso di cose o persone. Un fiume di persone si riversò nella piazza [Ibidem]. / На площадь хлынула река людей.

\section{montagna}

1. monte.

2. figurato mucchio, grande quantità (de ce qui afflue violemment). $C^{\prime} e^{\prime}$ una montagna di giocattoli davanti a me [Ibidem, p. 203]. / Передо мной гора игрушек.

Среднюю степень грамматикализации имеют квантификаторы, сочетающиеся не только с предметными, но и с абстрактными и/или вещественными именами.

Для итальянских квантификаторов неопределенно большого количества это следующие лексемы: abbondanza, afflusso, fascio, fila, fortuna, frutto, grappolo, groviglio, invasione, nuvola, voragine, vortice - изобилиe, наплыв, стопка, ряд, состояние, плоды, гроздья, клубок, нашествие, стайка, облако, пропасть, вихрь.

Например:

abbondanza

1. gran quantità;

2. ricchezza.

C'è abbondanza di cibo nella stiva della nave [Ibidem, p. 110]. / В трюме корабля изобилие пищи.

In quegli anni regnava l'abbondanza [Ibidem]. / В те годы дарил достаток (изобилие).

afflusso

1. di liquidi convergenti in un punto. L'eccessivo afflusso d'acqua provocò l'inondazione [Ibidem, p. 119]. / Чpe3мерный приток воды вызвал наводнение.

2. figurato affluenza. Il clima migliore ha portato un afflusso di turisti [Ibidem]. / Установившаяся погода принесла приток туристов.

\section{Заключение}

Итак, в результате исследования мы прошли к выводам о том, что список квантификаторов неопределённо большого количества в итальянском языке внушителен и включает в себя 29 количественных лексем. Мы также обнаружили основные степени грамматикализации итальянских квантитативных лексем - минимальную, среднюю и максимальную. Кроме того, нам удалось выявить степени грамматикализации исследуемых нами квантификаторов: среди итальянских предметных имен неопределенно большого количества минимальную грамматикализацию получили 4 лексемы. Максимально грамматикализованы 10 квантификаторов, что говорит о минимальных сочетаемостных ограничениях, и довольно много квантификаторов (13) имеют среднюю степень грамматикализации, что указывает на весьма интенсивную выраженность действия регулярной метафоры в итальянском языке: объем состояния или свойства отождествляется с количеством вещества.

Перспективы дальнейшего исследования данного лексического сектора заключаются в сопоставительном исследовании английских, итальянских и русских квантификативных предметных имен в аспекте выявления концептуальных сходств и различий между ними.

\section{Список источников}

1. Рахилина Е. В., Ли Су Хён. Семантика лексической множественности в русском языке // Вопросы языкознания. 2009. № 4. С. 13-40.

2. Сепир Э. Избранные труды по языкознанию и культурологии. М.: Прогресс, 1993. 656 с.

3. Тухтаходжаева 3. Т. Выражение категорий квантификации и оценки в словообразовательной системе современного английского языка. М.: Прогресс, 1981. 204 с.

4. Федяева Е. В. Категория «количество» - универсальная базовая категория человеческого сознания // Актуальные проблемы филологии и методики преподавания иностранных языков / отв. ред. А. М. Леонтьева. Новосибирск: Быстро!, 2007. С. 111-118.

5. Фесенко Т. А. Лингвоментальная модель процесса перевода // Язык, сознание, коммуникация: сборник статей. М.: Издательство МГУ, 2001. Вып. 20. С. 58-63. 
6. Хомский Н. Язык и мышление. Язык и проблемы знания. Благовещенск: БГК им. И. А. Бодуэна де Куртенэ, 1999. 123 с.

7. Челнокова А. А. Выражение разных видов количества в языке (на материале немецкого языка) // Вестник Самарского государственного университета. 2007. № 5. С. 229-234.

8. Чеснокова Л. Д. Категория количества и синтаксические структуры // Вопросы языкознания. 1981. № 2. C. $44-45$.

9. Швачко С. О. Екстеріоризація пізнавального процесу // Засоби квантифікації: лінгвокогнітивні аспекти: монографія / за редакцією проф. С. О. Швачко. Суми: Вид-во СумДУ, 2007. С. 14-21.

10. Шестак Л. А. Базовая метафорика в языковой картине мира (на материале языков разных типов) // Фразеологическая картина мира: материалы Международной научной конференции «Фразеология и миропонимание народа»: в 3-х ч. Тула: ТГПУ, 2006. Ч. 1. С. 124-128.

11. Doetjes J. Quantification at a distance and event relatedness [Электронный ресурc]. URL: https://pdfs. semanticscholar.org/d4f9/331b3d524aad24a983b8cf3a82d2374ddc4f.pdf (дата обращения: 17.03.2021).

12. http://www.collinsdictionary.com (дата обращения: 11.12. 2020).

13. Meillet A. L'évolution des formes grammaticales // Linguistique historique et linguistique générale / ed. Édouard Champion. P.: Librairie Ancienne Honoré Champion, 1921. P. 130-148.

14. Vocabolario della lingua italiana / di N. Zingarelli. Novara: Istituto Geografico DeAgostini, 2005. 1100 p.

\section{Информация об авторах | Author information}

RU Аксенова Ксения Александровна ${ }^{1}$, к. филол. н. Оборотова Елена Викторовна ${ }^{2}$

1,2 Липецкий государственный педагогический университет имени П. П. Семёнова-Тян-Шанского

EN Aksenova Ksenia Alexandrovna ${ }^{1}, \mathrm{PhD}$

Oborotova Elena Viktorovna ${ }^{2}$

${ }^{1,2}$ Lipetsk State Pedagogical P. Semenov-Tyan-Shansky University

${ }^{1}$ aksenova89@mail.ru, ${ }^{2}$ alyona.oborotova@ya.ru

\section{Информация о статье | About this article}

Дата поступления рукописи (received): 11.02.2021; опубликовано (published): 30.04.2021.

Ключевые слова (keywords): концепт НЕОПРЕДЕЛЕННОЕ КОЛИЧЕСТВО; квантификация; метафорИзация; квантитативная метафора; грамматикализация; concept INDEFINITE QUANTITY; quantification; metaphorization; quantitative metaphor; grammaticalization. 